\title{
Prognostic impact of body mass index stratified by smoking status in patients with esophageal squamous cell carcinoma
}

This article was published in the following Dove Press journal:

OncoTargets and Therapy

17 October 2016

Number of times this article has been viewed

\author{
Peng Sun ${ }^{1,2, *}$ \\ Fei Zhang ${ }^{1,2, *}$ \\ Cui Chen ${ }^{3, *}$ \\ Chao Ren ${ }^{1,2}$ \\ Xi-Wen $\mathrm{Bi}^{1,2}$ \\ Hang Yang ${ }^{1,2}$ \\ Xin $A n^{1,2}$ \\ Feng-Hua Wang ${ }^{1,2}$ \\ Wen-Qi Jiang ${ }^{1,2}$
}

'State Key Laboratory of Oncology in South China, Collaborative Innovation Center for Cancer Medicine,

2Department of Medical Oncology, Sun Yat-Sen University Cancer Center, ${ }^{3}$ Department of Oncology, the First Affiliated Hospital, Sun Yat-Sen University, Guangzhou, People's Republic of China

*These authors contributed equally to this work
Background: As smoking affects the body mass index (BMI) and causes the risk of esophageal squamous cell carcinoma (ESCC), the prognostic impact of BMI in ESCC could be stratified by smoking status. We investigated the true prognostic effect of BMI and its potential modification by smoking status in ESCC.

Methods: We retrospectively analyzed 459 patients who underwent curative treatment at a single institution between January 2007 and December 2010. BMI was calculated using the measured height and weight before surgery. Chi-square test was used to evaluate the relationships between smoking status and other clinicopathological variables. The Cox proportional hazard models were used for univariate and multivariate analyses of variables related to overall survival.

Results: BMI $<18.5 \mathrm{~kg} / \mathrm{m}^{2}$ was a significantly independent predictor of poor survival in the overall population and never smokers after adjusting for covariates, but not in ever smokers. Among never smokers, underweight patients $\left(B M I<18.5 \mathrm{~kg} / \mathrm{m}^{2}\right)$ had a 2.218 times greater risk of mortality than non-underweight $\left(\mathrm{BMI} \geq 18.5 \mathrm{~kg} / \mathrm{m}^{2}\right)$ patients $(P=0.015)$. Among ever smokers, $\mathrm{BMI}<18 \mathrm{~kg} / \mathrm{m}^{2}$ increased the risk of mortality to $1.656(P=0.019)$, compared to those having BMI $\geq 18 \mathrm{~kg} / \mathrm{m}^{2}$.

Conclusion: Our study is likely the first to show that the prognostic effect of BMI was substantial in ESCC, even after stratifying by smoking status. Furthermore, the risk of death due to low BMI would be significantly increased in never smokers. We believe that the prognostic impact of BMI is modified but not eliminated by the smoking status in ESCC.

Keywords: esophageal squamous cell carcinoma, ESCC, body mass index, BMI, smoking, prognosis, survival

\section{Introduction}

Esophageal cancer is one of the most common digestive cancers worldwide and remains one of the five leading causes of cancer-related deaths in People's Republic of China. ${ }^{1-3}$ In Asian Countries such as People's Republic of China and Japan, esophageal squamous cell carcinoma (ESCC) accounts for $>90 \%$ of all esophageal cancers with regard to histological classification. ${ }^{4-6}$ Although a trend toward reduced incidence of ESCC was observed, ESCC remains a serious threat to public health in People's Republic of China with a poor prognosis. ${ }^{1,2,4}$ Recent evidence has shown that low body mass index (BMI) increases the risk of developing ESCC, both in the Eastern ${ }^{7}$ and Western populations. ${ }^{8,9}$ Meanwhile, the prognostic effect of BMI has been discussed in multiple malignant diseases, ${ }^{10-15}$ and low BMI is seen as an unfavorable prognostic factor in facilitating appropriate therapeutic strategies for ESCC patients. 
Cigarette smoking might affect the prognostic impact of BMI on survival in ESCC. Smoking is known to affect BMI in the general population, ${ }^{16-20}$ in turn attenuating the prognostic effect of BMI in ESCC. However, smoking is an established risk factor ${ }^{21}$ and a potential prognostic factor of ESCC. ${ }^{22-25}$ Therefore, it is necessary to consider smoking status when evaluating BMI and prognosis in ESCC. In 2011, Yoon et al reported their data on esophageal adenocarcinoma and found that the unfavorable prognostic impact of high BMI was limited to never smokers. ${ }^{26}$ However, thus far, to the best of our knowledge, there is no similar data for ESCC. Thus, we hypothesized that the true prognostic value of BMI in ESCC may be better interpreted after stratifying by smoking status, or the effect may be underestimated in the nonsmoking population.

We conducted a retrospective study analyzing a large cohort of patients with ESCC. In order to eliminate the bias of treatment-related malnutrition, we limited the cohort to patients who underwent curative tumor resection and excluded those with preoperative chemotherapy and/or radiotherapy. We aimed to explore the prognostic value of BMI in smokers and nonsmokers who were treated with curative surgery.

\section{Methods}

\section{Ethics statement}

All patients provided written consent for their information to be stored in the Sun Yat-Sen University Cancer Center database and used for research. This study was conducted in accordance with the ethical standards of the World Medical Association's Declaration of Helsinki and approved by an independent ethics committee at the Cancer Center of Sun Yat-Sen University.

\section{Patients}

We retrospectively reviewed records of patients with ESCC who attended Sun Yat-Sen University Cancer Center between January 2007 and December 2010. All included subjects met the following criteria: 1) presence of pathologically diagnosed ESCC clinically evaluated to be at a localized or locoregional stage (stage I-III according to the sixth edition of the American Joint Committee on Cancer/Union for International Cancer Control Tumor-Node-Metastases [TNM] system); 2) availability of complete clinical data and disease records; and 3) disease management with radical esophagectomy. Patients who underwent preoperative therapy were excluded. Finally, 459 patients were included in the study (Figure 1).

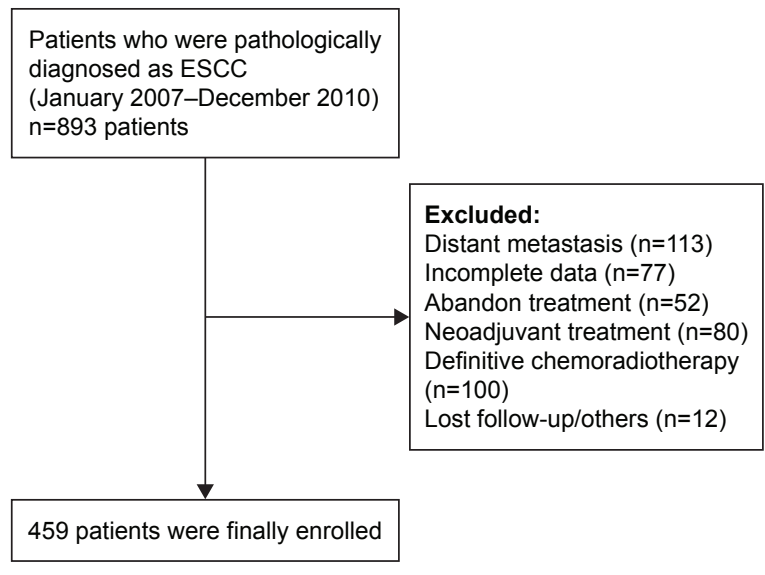

Figure I Flowchart displaying the patient selection. Abbreviation: ESCC, esophageal squamous cell carcinoma.

Basic demographics (age, sex) and baseline tumor characteristics (grade, stage) were collected for all patients. Height and weight was measured in the week prior to esophagectomy. Smoking status was recorded for all patients as ever or never smoker. A smoker was defined as an individual who smoked $\geq 1$ lifetime pack-years. Alcohol consumers were defined as those who drank any alcoholic beverage one or more times per week. On cessation of treatment, each patient was followed up every 3 months at the clinic or by telephonic contact and interview for at least 5 years. The last follow-up date was December 31, 2015.

\section{Statistical analyses}

The study's primary endpoint was overall survival (OS), defined as the time from the date of surgery to the date of death or the last follow-up visit. Patients were categorized by BMI into three subsets: underweight $\left(<18.5 \mathrm{~kg} / \mathrm{m}^{2}\right)$, normal weight $\left(18.5-24.99 \mathrm{~kg} / \mathrm{m}^{2}\right)$, and overweight or obese $\left(\geq 30 \mathrm{~kg} / \mathrm{m}^{2}\right) .{ }^{27} \mathrm{We}$ used Student's $t$-test and chi-square tests to compare continuous and categorical variables, respectively, between ever smokers and never smokers.

Given the previous data that underweight (BMI $<18.5 \mathrm{~kg} /$ $\mathrm{m}^{2}$ ) was associated with poor survival of ESCC, ${ }^{28,29}$ we combined the obese and normal weight groups in the survival analysis. The Kaplan-Meier method was used to estimate the 5-year OS, and the log-rank test was used to determine the survival differences. A stratified log-rank test was conducted with post hoc Bonferroni adjustment. Univariate and multivariate survival analyses were performed based on the Cox proportional hazards regression methodology. Hazard ratios with $95 \%$ confidence intervals (CIs) and two-sided $P$-values were reported. An alpha value of $P<0.05$ was considered 
statistically significant. All statistical analyses were performed using the Statistical Package for the Social Sciences, version 19.0 (IBM Corporation, Armonk, NY, USA).

\section{Results}

\section{Overall study population}

Baseline clinicopathological characteristics are listed in Table 1. A total of 459 patients (341 male and 118 female) with locoregional ESCC were enrolled. The median age of the cohort at initial diagnosis was 59 years. Tumors were pathologically confirmed as being of highly or moderately

Table I Baseline characteristics by smoking status in 459 patients with ESCC

\begin{tabular}{|c|c|c|c|c|c|c|c|}
\hline \multirow[t]{2}{*}{ Variable } & \multicolumn{2}{|c|}{ Overall } & \multicolumn{2}{|c|}{$\begin{array}{l}\text { Never } \\
\text { smokers }\end{array}$} & \multicolumn{2}{|c|}{$\begin{array}{l}\text { Ever } \\
\text { smokers }\end{array}$} & \multirow[t]{2}{*}{$P$-value } \\
\hline & No & $\%$ & No & $\%$ & No & $\%$ & \\
\hline Sex & & & & & & & $<0.00 \mathrm{I}^{*}$ \\
\hline Male & $34 I$ & 74.3 & 59 & 34.7 & 282 & 97.6 & \\
\hline Female & 118 & 25.7 & III & 65.3 & 7 & 2.4 & \\
\hline Age (years) & & & & & & & 0.123 \\
\hline Median & 59 & & 60 & & 58 & & \\
\hline Range & $34-88$ & & $40-88$ & & $34-87$ & & \\
\hline$<60$ & 243 & 52.9 & 82 & 48.2 & 161 & 55.7 & \\
\hline$\geq 60$ & 216 & 47.1 & 88 & 51.8 & 128 & 44.3 & \\
\hline Tumor grade & & & & & & & 1.000 \\
\hline I-II & 351 & 76.5 & 130 & 76.5 & 221 & 76.5 & \\
\hline III & 108 & 23.5 & 40 & 23.5 & 68 & 23.5 & \\
\hline TNM stage & & & & & & & $0.010 *$ \\
\hline I & 41 & 8.9 & 19 & 11.2 & 22 & 7.6 & \\
\hline II & 217 & 47.3 & 92 & 54.1 & 125 & 43.3 & \\
\hline III & 201 & 43.8 & 59 & 34.7 & 142 & 49.1 & \\
\hline Tumor location & & & & & & & 0.062 \\
\hline Upper & 40 & 8.7 & 15 & 8.8 & 25 & 8.7 & \\
\hline Middle & 287 & 62.5 & 117 & 68.8 & 170 & 58.8 & \\
\hline Lower & 132 & 28.8 & 38 & 22.4 & 94 & 32.5 & \\
\hline Alcohol drinking & & & & & & & $<0.00 I^{*}$ \\
\hline No & 301 & 65.6 & 159 & 93.5 & 142 & 49.1 & \\
\hline Yes & 158 & 34.3 & II & 6.5 & 147 & 50.9 & \\
\hline Body mass & & & & & & & $0.022 *$ \\
\hline \multicolumn{8}{|l|}{ index $\left(\mathrm{kg} / \mathrm{m}^{2}\right)$} \\
\hline Underweight & 60 & 13.1 & 13 & 7.6 & 47 & 16.3 & \\
\hline Normal & 318 & 69.3 & 122 & 71.8 & 196 & 67.8 & \\
\hline $\begin{array}{l}\text { Overweight or } \\
\text { obese }\end{array}$ & 81 & 17.6 & 35 & 20.6 & 46 & 15.9 & \\
\hline GPS & & & & & & & 0.728 \\
\hline 0 & 357 & 77.8 & 134 & 78.8 & 223 & 77.2 & \\
\hline $\mathrm{I}-2$ & 102 & 22.2 & 36 & 21.2 & 66 & 22.8 & \\
\hline Treatment & & & & & & & 0.526 \\
\hline Surgery alone & 378 & 82.4 & 143 & 84.1 & 235 & 81.3 & \\
\hline $\begin{array}{l}\text { Surgery }+ \\
\text { adjuvant RT/CT }\end{array}$ & 81 & 17.6 & 27 & 15.9 & 54 & 18.7 & \\
\hline
\end{tabular}

Note: $* p<0.05$.

Abbreviations: CT, chemotherapy; ESCC, esophageal squamous cell carcinoma; GPS, Glasgow Prognostic Score; RT, radiotherapy; TNM, Tumor-Node-Metastases. differentiated grade in 351 patients $(76.5 \%)$. By anatomic site, 287 tumors $(62.5 \%)$ were limited to the middle third of the esophagus. Forty-one (8.9\%), 217 (47.3\%), and 201 (43.8\%) patients were categorized as having American Joint Committee on Cancer/Union for International Cancer Control stage I, stage II, and stage III disease, respectively. Glasgow Prognostic Score (GPS) was also calculated, and most patients $(n=357,77.8 \%)$ presented with a presurgical GPS of zero. Overall, 289 patients (63\%) were smokers and 158 were alcohol drinkers $(34.3 \%)$. Among all the participants, 60 patients $(13.1 \%)$ were evaluated as underweight by BMI, 318 (69.3\%) had normal weight, and 81 (17.6\%) were overweight or obese.

In all, 378 patients $(82.4 \%)$ underwent radical resection and the other 81 patients $(17.6 \%)$ underwent surgery with postoperative treatment. Postoperative chemotherapy alone, radiotherapy alone, and concurrent chemoradiotherapy were used in $66(14.3 \%)$, three $(0.7 \%)$, and $12(2.6 \%)$ patients, respectively. Cisplatin, nedaplatin, fluorouracil, paclitaxel, and docetaxel were the most commonly delivered chemotherapy agents.

\section{Correlation of smoking with other clinicopathological features}

A significant male predominance and female predominance were observed in ever smokers and never smokers, respectively. Advanced tumors $(P=0.010)$, alcohol drinkers $(P<0.001)$, and overweight or obese patients $(P=0.022)$ were significantly higher among ever smokers $(n=289)$ than never smokers. Among never smokers $(\mathrm{n}=170), 13$ patients $(7.6 \%)$ were evaluated as underweight by BMI, 122 (71.8\%) had normal weight, and 35 (20.6\%) were overweight or obese. Among ever smokers ( $\mathrm{n}=289$; median, 37 pack-years), 47 patients $(16.3 \%)$ were evaluated as underweight by BMI, $196(67.8 \%)$ had normal weight, and 46 (15.9\%) were overweight or obese. The mean BMI values of never smokers and ever smokers were 22.67 and $21.74 \mathrm{~kg} / \mathrm{m}^{2}$, respectively (Student's $t$-test, $P=0.003$ ).

\section{Survival analyses}

The median follow-up time was 44 months (range, 1.3106.3 months). At the final follow-up time point, 255 patients had died. The median OS time for the entire patient group was 53.8 months, with 3- and 5-year OS rates of 58.2\% and $47.3 \%$, respectively. For the entire cohort, the median OS time for patients with low BMI $\left(<18.5 \mathrm{~kg} / \mathrm{m}^{2}\right)$ and high BMI ( $\geq 18.5 \mathrm{~kg} / \mathrm{m}^{2}$ ) was 29.8 and 60.9 months, respectively, 
with the 5-year OS rates being $27.2 \%$ and 50\%, respectively $(P=0.002)$. Besides BMI, TNM stage, drinking, smoking, GPS, and treatment approach were indicated as prognostic factors in the univariate analysis of OS. Multivariate analysis of OS was then conducted to confirm the prognostic effect of BMI. After adjusting for these covariates, BMI as well as TNM stage remained as independent prognostic factors of OS (Table 2; Figure 2A). We found that patients with a low BMI $\left(<18.5 \mathrm{~kg} / \mathrm{m}^{2}\right)$ had a 1.497 times greater mortality risk than those with a high BMI $\left(\geq 18.5 \mathrm{~kg} / \mathrm{m}^{2}\right)(95 \%$ $\mathrm{CI}=1.071-2.092, P=0.018)$.

In subgroup analysis of OS, the alpha value was defined as $0.025(0.05 / 2)$ by Bonferroni adjustment. Among never smokers, univariate analysis revealed that underweight patients had a significantly shorter OS than non-underweight patients (5-year OS rates: $15.4 \%$ vs $57.3 \%, P=0.009$ ) (Figure 2B). We further performed multivariate analysis of OS to explore the prognostic effect of BMI in never smokers. In addition to smoking status, TNM stage, alcohol consumption, GPS, and treatment approach that showed significance in the univariate analysis of the overall cohort were also included in the multivariate model. BMI was reconfirmed as an independent prognostic factor for never smokers with ESCC. Among never smokers, underweight patients $\left(\mathrm{BMI}<18.5 \mathrm{~kg} / \mathrm{m}^{2}\right)$ had a 2.218 times greater risk of mortality than the non-underweight $\left(\mathrm{BMI} \geq 18.5 \mathrm{~kg} / \mathrm{m}^{2}\right)$ patients $(95 \% \mathrm{CI}=1.164-4.224, P=0.015)$ (Table 3$)$.

Among ever smokers, non-underweight patients had a better OS than underweight patients, with only marginal statistical significance (5-year OS rates: $44.6 \%$ vs $40.8 \%$,

Table 2 Univariate and multivariate analyses of OS in 459 ESCC patients

\begin{tabular}{|c|c|c|c|c|c|c|c|c|}
\hline \multirow[t]{3}{*}{ Variable } & \multicolumn{4}{|c|}{ Univariate } & \multicolumn{4}{|c|}{ Multivariate } \\
\hline & \multirow[t]{2}{*}{$P$-value } & \multirow[t]{2}{*}{ HR } & \multicolumn{2}{|l|}{$95 \% \mathrm{Cl}$} & \multirow[t]{2}{*}{$P$-value } & \multirow[t]{2}{*}{ HR } & \multicolumn{2}{|l|}{$95 \% \mathrm{Cl}$} \\
\hline & & & Lower & Upper & & & Lower & Upper \\
\hline \multicolumn{9}{|l|}{ Sex } \\
\hline Male & & Reference & & & & & & \\
\hline Female & 0.061 & 0.757 & 0.566 & 1.013 & & & & \\
\hline \multicolumn{9}{|l|}{ Age (years) } \\
\hline$<60$ & & Reference & & & & & & \\
\hline$\geq 60$ & 0.193 & 1.177 & 0.921 & 1.505 & & & & \\
\hline \multicolumn{9}{|l|}{ Tumor grade } \\
\hline I-II & & Reference & & & & & & \\
\hline III & 0.144 & 1.232 & 0.931 & 1.632 & & & & \\
\hline \multicolumn{9}{|l|}{ TNM stage } \\
\hline I & & Reference & & & & Reference & & \\
\hline II & $0.002 *$ & 3.394 & 1.579 & 7.298 & $0.003^{*}$ & 3.190 & 1.483 & 6.864 \\
\hline III & $<0.00 I^{*}$ & 7.215 & 3.374 & 15.426 & $<0.001 *$ & 6.380 & 2.969 & 13.709 \\
\hline \multicolumn{9}{|l|}{ Tumor location } \\
\hline Upper & & Reference & & & & & & \\
\hline Middle & 0.818 & 0.949 & 0.608 & 1.480 & & & & \\
\hline Lower & 0.569 & 0.869 & 0.536 & 1.408 & & & & \\
\hline \multicolumn{9}{|l|}{ Alcohol drinking } \\
\hline No & & Reference & & & & Reference & & \\
\hline Yes & $0.004 *$ & 1.452 & 1.128 & 1.868 & 0.145 & 1.245 & 0.927 & 1.670 \\
\hline \multicolumn{9}{|l|}{ Smoking status } \\
\hline Never & & Reference & & & & Reference & & \\
\hline Ever & $0.028^{*}$ & 1.341 & 1.031 & I.743 & 0.708 & 1.060 & 0.781 & 1.438 \\
\hline \multicolumn{9}{|l|}{ Body mass index $\left(\mathrm{kg} / \mathrm{m}^{2}\right)$} \\
\hline$\geq 18.5$ & & Reference & & & & Reference & & \\
\hline$<18.5$ & $0.002 *$ & 1.673 & 1.205 & 2.323 & $0.018^{*}$ & 1.497 & $1.07 \mid$ & 2.092 \\
\hline \multicolumn{9}{|l|}{ GPS } \\
\hline 0 & & Reference & & & & Reference & & \\
\hline $\mathrm{I}-2$ & $0.008^{*}$ & 1.459 & 1.102 & 1.932 & 0.157 & 1.229 & 0.924 & 1.637 \\
\hline \multicolumn{9}{|l|}{ Treatment } \\
\hline Surgery alone & & Reference & & & & Reference & & \\
\hline Surgery + adjuvant RT/CT & $0.003 *$ & $\mathrm{I} .573$ & 1.166 & 2.122 & 0.363 & 1.156 & 0.846 & 1.579 \\
\hline
\end{tabular}

Note: $* p<0.05$.

Abbreviations: $\mathrm{Cl}$, confidence interval; CT, chemotherapy; ESCC, esophageal squamous cell carcinoma; GPS, Glasgow Prognostic Score; HR, hazard ratio; OS, overall survival; RT, radiotherapy; TNM, Tumor-Node-Metastases. 

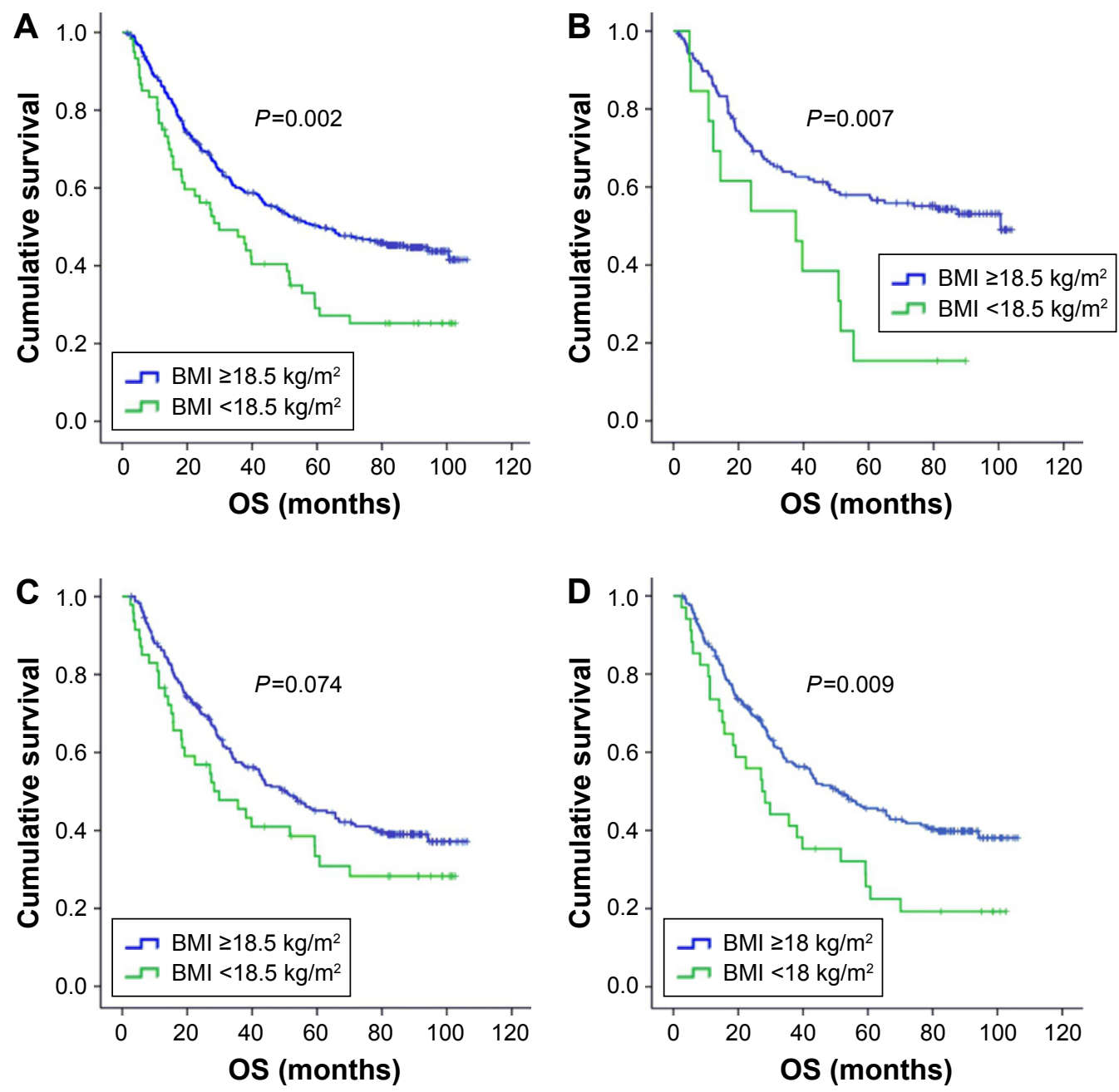

Figure 2 Kaplan-Meier curves for OS according to BMI in the entire study population.

Notes: (A) According to BMI in the entire study population, $(\mathbf{B})$ according to $\mathrm{BMI}$ in never smokers, (C) according to BMI in ever smokers and (D) according to the new categorization of BMI in ever smokers.

Abbreviations: BMI, body mass index; OS, overall survival.

$P=0.074$ ) (Table 3; Figure 2C). However, we identified a significant survival difference between smokers with BMI $<18 \mathrm{~kg} / \mathrm{m}^{2}$ and $\geq 18 \mathrm{~kg} / \mathrm{m}^{2}$ : smokers with a low BMI had a significantly shorter OS than those with
$\mathrm{BMI} \geq 18 \mathrm{~kg} / \mathrm{m}^{2}$ (5-year OS rates: $22.5 \%$ vs $\left.45.2 \%, P=0.009\right)$ (Figures 2D and 3). Multivariate analysis of OS demonstrated that BMI $<18 \mathrm{~kg} / \mathrm{m}^{2}$ was an independently unfavorable prognostic factor among ever smokers, after adjusting for

Table 3 Univariate and multivariate analyses of OS stratified by smoking status

\begin{tabular}{|c|c|c|c|c|c|c|c|}
\hline \multirow[t]{2}{*}{ Variable } & \multicolumn{3}{|l|}{ Univariate } & \multicolumn{3}{|c|}{ Multivariate } & \multirow[t]{2}{*}{ Alpha value } \\
\hline & OS time (months) & 5-year OS rate (\%) & $P$-value & $P$-value & HR & $95 \% \mathrm{Cl}$ & \\
\hline \multicolumn{8}{|l|}{ Never smokers } \\
\hline $\mathrm{BMI} \geq 18.5 \mathrm{~kg} / \mathrm{m}^{2}$ & 100.7 & 57.3 & $0.009 *$ & $0.015 *$ & 2.218 & I. $164-4.224$ & 0.025 \\
\hline $\mathrm{BMI}<18.5 \mathrm{~kg} / \mathrm{m}^{2}$ & 37.6 & 15.4 & & & & & \\
\hline \multicolumn{8}{|l|}{ Ever smokers } \\
\hline $\mathrm{BMI} \geq 18.5 \mathrm{~kg} / \mathrm{m}^{2}$ & 50.2 & 44.6 & 0.074 & 0.109 & 1.378 & $0.931-2.039$ & 0.025 \\
\hline $\mathrm{BMI}<\mathrm{I} 8.5 \mathrm{~kg} / \mathrm{m}^{2}$ & 29.8 & 30.8 & & & & & \\
\hline $\mathrm{BMI} \geq 18 \mathrm{~kg} / \mathrm{m}^{2}$ & 50.9 & 45.2 & $0.009 *$ & $0.019 *$ & 1.656 & $1.085-2.526$ & 0.025 \\
\hline $\mathrm{BMI}<18 \mathrm{~kg} / \mathrm{m}^{2}$ & 27.4 & 22.5 & & & & & \\
\hline
\end{tabular}

Note: $* P<0.025$.

Abbreviations: $\mathrm{BMI}$, body mass index; $\mathrm{Cl}$, confidence interval; $\mathrm{HR}$, hazard ratio; OS, overall survival. 


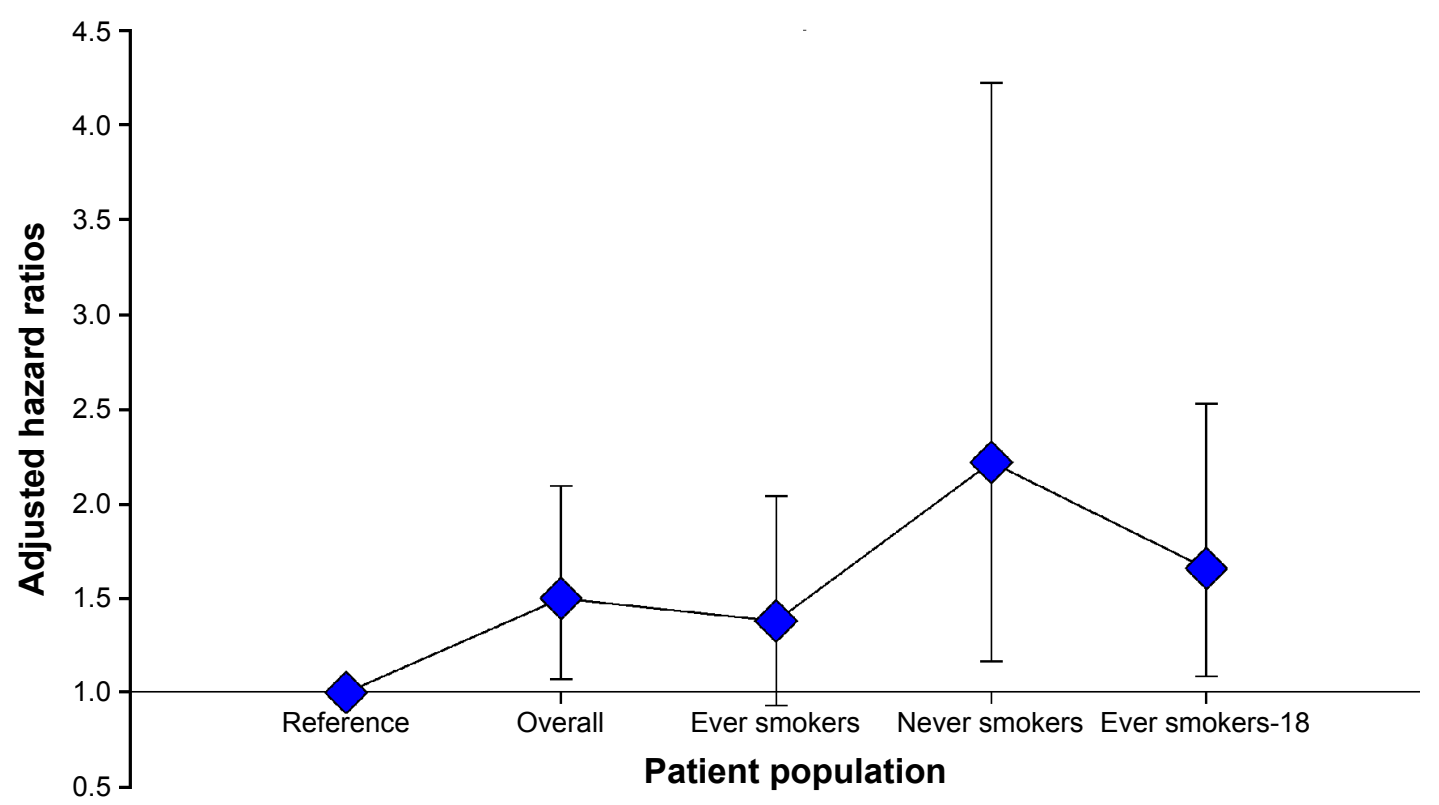

Figure 3 Adjusted HRs for OS according to BMI, stratified by smoking status. Note: "Ever smokers- 18 " indicates smokers with BMI $<18 \mathrm{~kg} / \mathrm{m}^{2}$.

Abbreviations: BMI, body mass index; HRs, hazard ratios; OS, overall survival.

TNM stage, alcohol consumption, GPS, and treatment approach. Compared to those with BMI $\geq 18 \mathrm{~kg} / \mathrm{m}^{2}$, low BMI $\left(<18 \mathrm{~kg} / \mathrm{m}^{2}\right)$ increased the mortality risk for ever smokers with ESCC to $1.656(95 \%$ CI $=1.085-2.526$, $P=0.019$ ) (Table 3).

\section{Discussion}

BMI is a parameter that roughly reflects an individual's nutritional status and can be feasibly and conveniently obtained in clinical practice. Recently, the role of BMI has been increasingly appreciated, as the strong relationship between BMI and the risk of ESCC was established in previous studies. ${ }^{7-9}$ In 2001, Gallus et al performed a large case-control study and reported that leanness appeared to be an indicator of ESCC. ${ }^{9}$ In 2008, Smith et $\mathrm{al}^{7}$ conducted a meta-analysis including ten studies and found significant inverse associations between BMI and the risk of ESCC in both Western and Asian populations. This finding was confirmed by Lahmann et al, ${ }^{8}$ who further showed that these associations were independent of smoking status.

Other than being an epidemiological risk factor, BMI was also recognized as a prognostic factor for ESCC. In the meta-analysis by Smith et al, ${ }^{7}$ the risk of mortality in ESCC decreased by $31 \%$ for a $5 \mathrm{~kg} / \mathrm{m}^{2}$ increase in BMI. French oncologists found that a low BMI $\left(<18 \mathrm{~kg} / \mathrm{m}^{2}\right)$ was associated with inferior survival in $87 \mathrm{ESCC}$ cases with definitive chemoradiotherapy, ${ }^{30}$ which was consistent with data from another French study reported by Clavier et al. ${ }^{31}$ The poor prognosis of low BMI was also identified in two other Chinese studies. ${ }^{28,29}$ Consistent with these results, we also confirmed, in our large retrospective study, the unfavorable impact of low BMI $\left(<18.5 \mathrm{~kg} / \mathrm{m}^{2}\right)$ on survival in locoregional ESCC.

Although studies ${ }^{28,29}$ exploring the prognostic effect of BMI in ESCC showed encouraging results, the role of smoking status could not be ignored in the interpretation of BMI data for several critical reasons. First, smoking status might negatively affect individual body weight and BMI. Second, smoking status itself is a well-known risk factor and a potential prognostic factor as propounded by multiple studies. ${ }^{14,22,32,33}$ The complex interaction between BMI and smoking status of cancer patients has been revealed by several studies, ${ }^{18-20}$ although with inconsistent data. In addition, few studies have explored the influence of smoking status on the association between BMI and the risk of ESCC, with discordant results. ${ }^{8,9,34}$ However, to our best knowledge, the prognostic value of BMI stratified by smoking status in ESCC has thus far not been evaluated. Only one study has discussed this issue, but with respect to esophageal adenocarcinoma. In 2011, Yoon et $\mathrm{al}^{26}$ retrospectively analyzed cases of esophageal adenocarcinoma from the Mayo Esophageal Cancer Outcomes Database. In that study, obesity (BMI $\geq 30 \mathrm{~kg} / \mathrm{m}^{2}$ ) was independently associated with a worsened prognosis among never smokers, but not among ever smokers. Accordingly, in our study, the adverse impact of BMI $<18.5 \mathrm{~kg} / \mathrm{m}^{2}$ was limited to never smokers in the 
stratified analysis. Multivariate survival analysis using the Cox model showed that low BMI $\left(<18.5 \mathrm{~kg} / \mathrm{m}^{2}\right)$ was independently associated with impaired OS. By contrast, low BMI $\left(<18.5 \mathrm{~kg} / \mathrm{m}^{2}\right)$ was not a significantly poor prognostic factor of OS ( $P=0.074)$ among ever smokers. Therefore, our results explored and highlighted the importance of smoking status in the interpretation of BMI data in patients with ESCC. Furthermore, the hazard ratio of low BMI $\left(<18.5 \mathrm{~kg} / \mathrm{m}^{2}\right)$ increased from 1.497 for the entire cohort to 2.218 for never smokers, indicating that the prognostic effect was amplified with the exclusion of ever smokers.

A possible explanation for this interesting finding was proposed by the authors from Mayo Clinic. ${ }^{26}$ Leptin could promote tumor progression and invasion in digestive cancers, whereas cigarette smoking could decrease the circulating leptin and enhance its receptors. Thus, Yoon et al ${ }^{26}$ considered the prognostic impact of obesity was weakened in esophageal adenocarcinoma by smoking. However, this explanation could not be merely extended to ESCC owing to its apparent etiological and epidemiological differences. Because of a relatively high prevalence of cancer-related dysphagia and cachexia, patients with ESCC might present with low BMI in contrast to those with esophageal adenocarcinoma. On the other hand, the BMI of the Asian population is considered lower than that of the Western population. ${ }^{26,28}$ These aspects must be taken into consideration while determining the relationship between BMI, smoking, and prognosis in ESCC.

Several population-based studies have explored the interaction between smoking and BMI, as smoking has shown to be associated with decreased BMI. Wehby et al ${ }^{35}$ applied genetic tools to identify the effects of smoking on body weight and detected heterogeneity in these effects across the BMI distribution in a Norwegian population. Their results revealed that smoking had a negative impact on BMI of the population with high BMI. ${ }^{35}$ Kasteridis and Yen ${ }^{36}$ analyzed the population from the Behavioral Risk Factor Surveillance Survey and showed a positive association between body weight gain and smoking cessation. Wang ${ }^{16}$ explored the data obtained from the China Health and Nutrition Survey 1991-2011 and found a positive effect of smoking on underweight and healthy weight. Su et $\mathrm{a}^{37}$ found that smoking had an effect on decreasing BMI of middle-aged and older Chinese males, based on the data from the Chinese Physical and Psychological Database. In addition, the weight-reducing effect of smoking on BMI has been further explored in single-nucleotide polymorphism studies. ${ }^{38}$ Smoking status was found to modify the association between
$15 \mathrm{q} 25$ variant of CHRNA5-CHRNA3-CHRNB4 gene and BMI, providing reliable evidence that smoking exposure reduces the BMI. ${ }^{39}$

Based on the available BMI-smoking data, we suggested that the reduction of BMI due to smoking weakened its impact of survival in ever smokers with ESCC. The present study provided evidence to support this opinion. Our data showed a relatively lower BMI for ever smokers than never smokers (mean BMI: $22.67 \mathrm{vs} 21.74 \mathrm{~kg} / \mathrm{m}^{2}$, Student's $t$-test, $P=0.003$ ). We then hypothesized that the significant prognostic effect of low BMI could be detected if we decreased the BMI cutoff value. In order to validate our hypothesis, we regrouped the participants into two groups, patients with BMI $\geq 18 \mathrm{~kg} / \mathrm{m}^{2}$ and those with BMI $<18 \mathrm{~kg} / \mathrm{m}^{2}$, by referring to the experience of a previous study. ${ }^{30}$ Low BMI $\left(<18 \mathrm{~kg} / \mathrm{m}^{2}\right)$ was found to be independently associated with poor prognosis among ever smokers, even after adjusting for other covariates. This finding partly suggested that the prognostic effect of BMI in ESCC was modified but not abolished in ever smokers with ESCC. The results in Yoon's study might be different if they had changed the definition of obese by altering the categorization of BMI. ${ }^{26}$ Therefore, adequate classification of BMI is important in certain populations such as in Asians, in ESCC, or in ever smokers, in order to gain accurate prognostic information of BMI.

The main merits of our study include the relatively large sample size and histological homogeneity with regard to ESCC, representing a clinical entity in the Chinese patient population. The demographic characteristics of our cohort were in line with previous data. ${ }^{2,4} \mathrm{BMI}$ was calculated from body weight and height prospectively measured by trained nurses at a uniform time point relative to surgery, instead of relying on self-reported weight and height measurements as in another study. ${ }^{8}$ In addition, patients who underwent neoadjuvant therapy were excluded to avoid the situation of potential treatment-related BMI decrease.

Our study also has some limitations. First, there was inherent bias owing to the study's retrospective design, although the height and weight measurements were prospectively recorded. Second, the significant male predominance in our cohort might limit the applicability of our findings to females, especially among ever smokers. Third, we did not further discuss the association between BMI and postoperative comorbidities due to insufficient data. Finally, the low percentage (13.1\% overall, $7.1 \%$ in never smokers) of underweight patients (BMI $<18.5 \mathrm{~kg} / \mathrm{m}^{2}$ ) should be acknowledged. Therefore, it is important to validate our findings in a prospective study from an independent cohort. 


\section{Conclusion}

We conclude that there is a substantial prognostic effect of BMI on Chinese patients with ESCC, after accounting for the effects of other factors. The adverse effect of low BMI on survival in ESCC was robust and amplified in never smokers, and this effect remained significant in ever smokers. We also found that smokers showed a relatively low BMI, which probably contributed to the modifications of smoking on the prognostic effect of BMI in ESCC. Genetic tools should be applied to elucidate the biologic mechanisms underlying the interaction between smoking, BMI, and cancer prognosis. In particular, the prognostic information of BMI was important to facilitate risk stratification, refine postoperative treatment approach, and assist with nutritional support for patients with ESCC.

\section{Disclosure}

The authors report no conflicts of interest in this work.

\section{References}

1. Napier KJ, Scheerer M, Misra S. Esophageal cancer: a review of epidemiology, pathogenesis, staging workup and treatment modalities. World J Gastrointest Oncol. 2014;6(5):112-120.

2. Zhang Y. Epidemiology of esophageal cancer. World J Gastroenterol. 2013;19(34):5598-5606.

3. Chen W, Zheng R, Baade PD, et al. Cancer statistics in China, 2015. CA Cancer J Clin. 2016;66(2):115-132.

4. Lin Y, Totsuka Y, He Y, et al. Epidemiology of esophageal cancer in Japan and China. J Epidemiol. 2013;23(4):233-242.

5. Zhang HZ, Jin GF, Shen HB. Epidemiologic differences in esophageal cancer between Asian and Western populations. Chin J Cancer. 2012; 31(6):281-286.

6. Chen W, Zheng R, Zhang S, Zhao P, Zeng H, Zou X. Report of cancer incidence and mortality in China, 2010. Ann Transl Med. 2014;2(7):61.

7. Smith M, Zhou M, Whitlock G, et al. Esophageal cancer and body mass index: results from a prospective study of 220,000 men in China and a meta-analysis of published studies. Int J Cancer. 2008;122(7):1604-1610.

8. Lahmann PH, Pandeya N, Webb PM, Green AC, Whiteman DC. Body mass index, long-term weight change, and esophageal squamous cell carcinoma: is the inverse association modified by smoking status. Cancer. 2012;118(7):1901-1909.

9. Gallus S, La Vecchia C, Levi F, Simonato L, Dal Maso L, Franceschi S. Leanness and squamous cell oesophageal cancer. Ann Oncol. 2001;12(7): 975-979.

10. Hemminki K, Chen B, Melander O, Manjer J, Hallmans G, Hemminki A. Smoking and body mass index as risk factors for subtypes of cancer of unknown primary. Int J Cancer. 2015;136(1):246-247.

11. Fowke JH, McLerran DF, Gupta PC, et al. Associations of body mass index, smoking, and alcohol consumption with prostate cancer mortality in the Asia Cohort Consortium. Am J Epidemiol. 2015;182(5): 381-389.

12. Pelucchi C, Galeone C, Polesel J, et al. Smoking and body mass index and survival in pancreatic cancer patients. Pancreas. 2014;43(1): 47-52.

13. Park B, Jeong BC, Seo SI, Jeon SS, Choi HY, Lee HM. Influence of body mass index, smoking, and blood pressure on survival of patients with surgically-treated, low stage renal cell carcinoma: a 14-year retrospective cohort study. J Korean Med Sci. 2013;28(2):227-236.
14. Sunela KL, Kataja MJ, Kellokumpu-Lehtinen PL. Influence of body mass index and smoking on the long-term survival of patients with renal cell cancer. Clin Genitourin Cancer. 2013;11(4):458-464.

15. Liu D, Li Q, Yang Z, et al. Association of body mass index and smoking on outcome of Chinese patients with colorectal cancer. World J Surg Oncol. 2013;11:271.

16. Wang Q. Smoking and body weight: evidence from China health and nutrition survey. BMC Public Health. 2015;15:1238.

17. McFadden E, Luben R, Wareham N, Bingham S, Khaw KT. Occupational social class, educational level, smoking and body mass index, and cause-specific mortality in men and women: a prospective study in the European Prospective Investigation of Cancer and Nutrition in Norfolk (EPIC-Norfolk) cohort. Eur J Epidemiol. 2008;23(8): 511-522.

18. Adams KF, Schatzkin A, Harris TB, et al. Overweight, obesity, and mortality in a large prospective cohort of persons 50 to 71 years old. N Engl J Med. 2006;355(8):763-778.

19. de Gonzalez AB, Hartge P, Cerhan JR, et al. Body-mass index and mortality among 1.46 million white adults. N Engl J Med. 2010;363(23): 2211-2219.

20. Pischon T, Boeing H, Hoffmann K, et al. General and abdominal adiposity and risk of death in Europe. $N$ Engl J Med. 2008;359(20): 2105-2120.

21. Wang JM, Xu B, Rao JY, Shen HB, Xue HC, Jiang QW. Diet habits, alcohol drinking, tobacco smoking, green tea drinking, and the risk of esophageal squamous cell carcinoma in the Chinese population. Eur J Gastroenterol Hepatol. 2007;19(2):171-176.

22. Shitara K, Matsuo K, Hatooka S, et al. Heavy smoking history interacts with chemoradiotherapy for esophageal cancer prognosis: a retrospective study. Cancer Sci. 2010;101(4):1001-1006.

23. Sundelöf M, Lagergren J, Ye W. Patient demographics and lifestyle factors influencing long-term survival of oesophageal cancer and gastric cardia cancer in a nationwide study in Sweden. Eur J Cancer. 2008; 44(11):1566-1571.

24. Wang N, Tan B, Cao F, et al. Prognostic influence of smoking on esophageal squamous cell carcinoma. Int J Clin Exp Med. 2015;8(10): 18867-18872.

25. Zheng Y, Cao X, Wen J, et al. Smoking affects treatment outcome in patients with resected esophageal squamous cell carcinoma who received chemotherapy. PLoS One. 2015;10(4):e0123246.

26. Yoon HH, Lewis MA, Shi Q, et al. Prognostic impact of body mass index stratified by smoking status in patients with esophageal adenocarcinoma. J Clin Oncol. 2011;29(34):4561-4567.

27. Medehouenou TC, Ayotte P, St-Jean A, et al. Overweight and obesity prevalence among school-aged Nunavik Inuit children according to three body mass index classification systems. J Adolesc Health. 2015;57(1):31-36.

28. Ren C, Cai XY, Qiu MZ, et al. Impact of body mass index on survival of esophageal squamous carcinoma patients in southern China. J Thorac Dis. 2015;7(3):337-345.

29. Sun P, Zhang F, Chen C, et al. Comparison of the prognostic values of various nutritional parameters in patients with esophageal squamous cell carcinoma from Southern China. J Thorac Dis. 2013;5(4): 484-491.

30. Di FF, Lecleire S, Pop D, et al. Baseline nutritional status is predictive of response to treatment and survival in patients treated by definitive chemoradiotherapy for a locally advanced esophageal cancer. Am J Gastroenterol. 2007;102(11):2557-2563.

31. Clavier JB, Antoni D, Atlani D, et al. Baseline nutritional status is prognostic factor after definitive radiochemotherapy for esophageal cancer. Dis Esophagus. 2014;27(6):560-567.

32. Pierce JP, Patterson RE, Senger CM, et al. Lifetime cigarette smoking and breast cancer prognosis in the After Breast Cancer Pooling Project. $J$ Natl Cancer Inst. 2014;106(1):djt359.

33. Janjigian YY, McDonnell K, Kris MG, et al. Pack-years of cigarette smoking as a prognostic factor in patients with stage IIIB/IV nonsmall cell lung cancer. Cancer. 2010;116(3):670-675. 
34. Steffen A, Schulze MB, Pischon T, et al. Anthropometry and esophageal cancer risk in the European prospective investigation into cancer and nutrition. Cancer Epidemiol Biomarkers Prev. 2009;18(7): 2079-2089.

35. Wehby GL, Murray JC, Wilcox A, Lie RT. Smoking and body weight: evidence using genetic instruments. Econ Hum Biol. 2012;10(2): 113-126.

36. Kasteridis P, Yen ST. Smoking cessation and body weight: evidence from the Behavioral Risk Factor Surveillance Survey. Health Serv Res. 2012;47(4):1580-1602.
37. Su P, Hong L, Sun H, Zhao YF, Li L. Age plays an important role in the relationship between smoking status and obesity risk: a large scale cross-sectional study of Chinese adults. Int J Clin Exp Med. 2015;8(10): 18894-18906.

38. Taylor AE, Morris RW, Fluharty ME, et al. Stratification by smoking status reveals an association of CHRNA5-A3-B4 genotype with body mass index in never smokers. PLoS Genet. 2014;10(12):e1004799.

39. Freathy RM, Kazeem GR, Morris RW, et al. Genetic variation at CHRNA5-CHRNA3-CHRNB4 interacts with smoking status to influence body mass index. Int J Epidemiol. 2011;40(6):1617-1628.

\section{Publish your work in this journal}

OncoTargets and Therapy is an international, peer-reviewed, open access journal focusing on the pathological basis of all cancers, potential targets for therapy and treatment protocols employed to improve the management of cancer patients. The journal also focuses on the impact of management programs and new therapeutic agents and protocols on

\section{Dovepress}

patient perspectives such as quality of life, adherence and satisfaction. The manuscript management system is completely online and includes a very quick and fair peer-review system, which is all easy to use. Visit http://www.dovepress.com/testimonials.php to read real quotes from published authors.

Submit your manuscript here: http://www.dovepress.com/oncotargets-and-therapy-journal 